\title{
Effectiveness of Commonly Used Antibiotics in Combination with Honey Against Bacterial Infection
}

\author{
Niraj Shrestha ${ }^{1}$, Shova Shrestha ${ }^{1}$, Bharat Mani Pokharel ${ }^{2}$ \\ ${ }^{1}$ Department of Microbiology, Tri-Chandra Multiple Campus, Ghantaghar, Kathmandu, Nepal \\ ${ }^{2}$ Department of Microbiology, Institute of Medicine (IOM, TUTH), Kathmandu, Nepal
}
Corresponding author: Shova Shrestha, Associate Professor, Department of Microbiology, Tri-Chandra Multiple Campus, Ghantaghar, Kathmandu, Nepal; Email:shova_23@hotmail.com

\begin{abstract}
Objectives: The study was carried out to compare the inhibitory effects between commonly used antibiotics and bee honey samples, so as to correlate the inhibitory effects between bee honey alone and in combination with antibiotics.
\end{abstract}

Methods: This study was carried out between December 2012 to September 2013. A total of one hundred and twenty-two clinical microbiological specimens and five different floral sourced honey samples were collected between December 2012 to September 2013. Twenty-three multi-drug resistant organisms were selected. Then, AST for commonly used antibiotics, honey alone and combination of honey-antibiotics discs was done. The difference in ZOI of antibiotic contrasting with the antibiotics containing honey were statistically analysed to define the synergism.

Results: The inhibition due to honey is variable among bacteria types $(\mathrm{F}=39.17, \mathrm{p}<0.05)$. From means plot, Staphylococcus and Acinetobacter were recognized as highly susceptible bacteria for honey $(\bar{x}=21.1 \pm 6.2 \mathrm{~mm}$ and $\bar{X}=18.3 \pm 3.3 \mathrm{~mm}$ respectively) but Acinetobacter species could not show synergism to honey-antibiotic combination. The tested organisms from Enterobacteriaceae family showed effective susceptibility to Chloramphenicol-honey mixture. Imipenem-honey combination and Gentamicin-honey combination showed significant effects against Pseudomonas aeruginosa.

Conclusion: Thus, honey can be used in various bacteria-directed infections and found to be effective in various infections. Incorporation of honey in antibiotics like Chloramphenicol, Imipenem, and Gentamicin works better in healing various infection.

Key words: Honey, Antibiotics, Synergism, Antibiotic-honey combination

\section{INTRODUCTION}

Honey has four modes for the antibacterial effects (Molan 1992). They are osmophilic effect (Molan 1992), acidic pH (Nassar et al. 2012), hydrogen peroxide production due to glucose oxidase of bee gut (Irish et al. 2011, Bizerra et al. 2012), and antioxidants such as catalases, polyphenols, Maillard reaction products and ascorbic acid (Bizerra et al. 2012) and other components in nectar produced by the plants (Molan 1992).

It is bacteriostatic and bactericidal for gram positive and gram-negative bacteria (Pimentel et al. 2013). It also possesses antifungal character (Lane et al. 2019)

Date of Submission: September 22, 2020

Published Online: December, 2020 and can be used against antibiotic resistant bacteria (Sharp 2009) like MRSA (Müller et al. 2013) and VRE (Boukraâ and Sulaiman 2009).

The protein now identified as universal stress protein A (UspA) is involved in the stress stamina response and its down-regulation could help to explain the inhibition of MRSA of Manuka honey. The level of expression was found to be changed at least two-folds following treatment with the honey (Jenkins et al. 2011).

However, a review article and meta-analysis suggests that the previous works are not sufficient to prove the

Date of Acceptance: November 5, 2020

DOI: https:/ / doi.org/10.3126/tujm.v7i0.33797 
antimicrobial effects of honey (Wijesinghe et al. 2009). In Nepal, the similar studies were performed where honey samples used were not measured properly during the tests. Thus, this study was carried out to determine the present condition of bacteria for the susceptibility towards natural compound honey and to define the statistically significant synergism with various antibiotics.

\section{MATERIALS AND METHODS}

This study was performed between December 2012 to September 2013. One hundred and twenty-two microbiological specimens included pus specimen, wound swabs, blood, urine, body fluids were obtained for routine culture in microbiology laboratory.

Sample collection:

1. Study population: All age groups and both sexes visiting $\mathrm{KNFH}$ were included from whom the samples were obtained for routine culture and AST. Patients or their relatives refusing to give informed consents were excluded from the study. The samples from the patients who were already in medication were also excluded from the data.

2. Collection and transportation of clinical specimen:

(a) Pus samples: A sterile cotton swab moistened with physiological saline was used to collect two pus swabs from each patient, one for Gram staining and other for culture. The both swabs were transported aseptically to laboratory for further processing.

(b) Blood samples: 1 volume of blood sample collected from the patient was mixed with 5 volume of Brain Heart Infusion (BHI) and transported to laboratory for further processing.

(c) Urine samples: About 10 to $20 \mathrm{ml}$ of midstream urine sample was collected in a sterile container and transported to laboratory for further processing.

3. Processing of samples: Pus samples were observed for their consistency and blood contents. The physical appearance of urine samples was recorded for future reference.

The pus samples, blood samples, and the urine samples were streaked on Nutrient Agar (NA), Blood Agar (BA) then MacConkey Agar (MA). The plates were incubated at $37 \pm 0.2{ }^{\circ} \mathrm{C}$ for 24 to 48 hours. The colour, appearance, $\mathrm{pH}$ and turbidity of urine were evaluated during macroscopic examination of the urine sample (Vandepitte et al. 2003 Collee et al. 2001). The urine samples were cultured onto the BA and MA plates by the semi-quadrant streak technique using a standard calibrated loop having internal diameter of $4 \mathrm{~mm}$. The protocol was followed as recommended by WHO (Vandepitte et al. 2003). The plates were then aerobically incubated at $37 \pm 0.2^{\circ} \mathrm{C}$ for 24 to 48 hours before reporting negative. Semi-quantitative counting method was performed to calculate the number of cfu $\mathrm{mL}^{-1}$ of urine and the bacterial count was reported as:

Significant bacteriuria:

- Urine containing more than $10^{5}(100000)$ bacteria per $\mathrm{ml}$ that is $10^{5} / \mathrm{ml}$ urine-is an indication of UTI.

- Women with symptomatic UTI $\geq 10^{5} \mathrm{cfu} \mathrm{mL}^{-1}$ :

- Men $\geq 10^{3} \mathrm{cfu} \mathrm{mL}^{-1}$ (if $80 \%$ of the growth is due to single organism in both cases) (Scottish Intercollegiate Guidelines Network, 2012).

If the culture indicates presence of two uropathogens both showing significant growth, definitive identification and antimicrobial susceptibility testing of both were performed whereas in case of $\geq 3$ pathogens, it was reported as multiple bacterial morphotypes and asked for appropriate recollection with timely delivery to laboratory (Vandepitte et al. 2003).

The culture plates were examined for the visual growth of the organisms. The colour and the morphology of the colonies were observed carefully. Then biochemical tests were performed for the isolated colonies for their identification.

Antibiotic susceptibility test (AST) by Kirby Bauer disc diffusion method was performed to select out the drug resistant organisms and multiple drug resistant organisms were selected for the study. The organism which showed resistance to at least three or more antibiotics of different classes were considered as MDR (Sahm et al. 2000). For the identification of the characters, the ZOI chart provided by CLSI guidelines (2011) was followed. Five honey samples of various origins and of two varieties of bees (Apis mellifera and Apis dorsata) were used for the tests.

Honey discs were prepared by using dry sterile filter 
papers of same thickness $(1 \mathrm{~mm})$ and same size $(6$ $\mathrm{mm}$ diameter) as the antibiotic discs on which about 50 microlitres of honey samples were dispensed individually. Same volume was poured on antibiotic discs to meet the concentration same as honey discs used. To ensure the transfer of same volume of honey, calibration of the micropipette was done at regular interval of time. The following steps were followed for the calibration. $1 \mathrm{ml}$ of deionized water was carefully pipetted into the plate in a sensitive balance. Its weight was measured. After continuous repetition for 3 times, the average weight was calculated. Then the following formula was used to calculate the accuracy of the pipette. accuracy $(\%)=\frac{\text { Pipette volume }- \text { average value }}{\text { Pipette volume }} \times 100(\%)$

All the bacterial isolates were tested for antibiotic susceptibility test by Kirby Bauer disc diffusion method with Mueller-Hinton Agar using the guidelines and interpretive criteria of the CLSI guidelines (CLSI 2011). The antibiotic discs used were Amoxycillin-Clavulanic acid $(20 / 10 \mu \mathrm{g})$, Ceftazidime $(30 \mu \mathrm{g})$, Ceftriaxone $(30 \mu \mathrm{g})$, Chloramphenicol $(30 \mathrm{~g})$, Ciprofloxacin $(5 \mu \mathrm{g})$, Cotrimoxazole $(1.25 / 23.75 \mu \mathrm{g})$, Gentamicin (30 $\mu \mathrm{g})$, Imipenem $(10 \mu \mathrm{g})$, and Oxacillin $(1 \mu \mathrm{g})$. The diameter of Zone of Inhibition (ZOI) was recorded for each disc. During this procedure, the measured diameter for honey discs was deducted from the diameter of the sterile discs.

The differences in Zone of inhibition (ZOI) of antibiotic contrasting with the antibiotic containing honey were statistically analysed to define the synergism. Data entry was performed using Microsoft ${ }^{\circledR}$ Excel $^{\circledR}$ and data analysis was performed using Statistical Package for Social Sciences (SPSS ${ }^{\circledR} 16.0$ for Windows ${ }^{\circledR}$ ) software. The one-tailed t-statistics with $\alpha$ value $1 \%$ was implied for the statistical confirmation.

The following formula was used to calculate the test statistics t:

$t=\frac{\bar{x}_{\text {diff }}}{\sqrt{n}}$

$\bar{x}_{\text {diff }}=$ where

$s=$ sample mean of the differences

$\mathrm{s}=$ sample standard deviation of the differences

$\mathrm{n}=$ sample size (i.e. number of pairs)

Null hypothesis setup: There is no difference in the use of honey and antibiotic or antibiotic alone $\left(\mu_{1}-\mu_{2} \geq 0\right)$.

Alternate hypothesis setup: There is enhanced effect of honey and antibiotic than antibiotic alone $\left(\mu_{1}-\mu_{2}<0\right)$.

\section{Quality control}

Laboratory equipment like incubators, hot air oven, autoclave, refrigerator etc. were regularly monitored for their performance and immediately corrected if any deviation occurred. The temperature of the incubators and refrigerator were monitored every day. Reagents and biochemical media were checked for manufacture and expiry date and proper storage. After preparation, each media and reagent were labelled with preparation date, expiry date and stored in proper conditions. Sterility testing and performance testing were carried out using standard control strains.

\section{Quality control during isolation and identification} Culture media that passed quality control for performance and sterility were used. During the identification, pure and isolated colony of the organism was used. After inoculation into different biochemical media, the inoculum was verified for pure culture and no contamination occurred during inoculation.

\section{Quality control during antimicrobial susceptibility testing}

Muller Hinton agar and antibiotic disc were checked for each lot number, manufacture date and expiry date and stored properly. Before use, each antibiotics disc and Muller Hinton Agar was monitored for their performance quality with E. coli ATCC 25922 and S. aureus ATCC 25923. For antimicrobial susceptibility testing, standard inoculum (matched with 0.5 McFarland solutions) was used.

\section{RESULTS}

Twenty three culture positive samples were collected from Korea Nepal Friendship Hospital (KNFH). Among them, six $(26.09 \%)$ were S. aureus, one was coagulase negative staphylococcus (CONS), eight (34.78\%) were E. coli, four $(17.39 \%)$ were Klebsiella species and again four $(17.39 \%)$ were Salmonella species. After screening by AST, 10 samples (43.48\%) were finalized as multidrug resistant. In addition, 4 metallo- $\beta$-lactamase producers (2 Acinetobacter species and 2 Pseudomonas aeruginosa) (that were helped by Mr. Saroj Chandra Lohani, a researcher of Birendra Sainik Hospital, Chhauni) were also used for the study.

Among the 10 isolates collected from KNFH, 4 were MDR S. aureus (17.39\%), 2 each were MDR E. coli $(8.70 \%)$, MDR Klebsiella species $(8.70 \%)$ and MDR Salmonella species $(8.70 \%)$. 


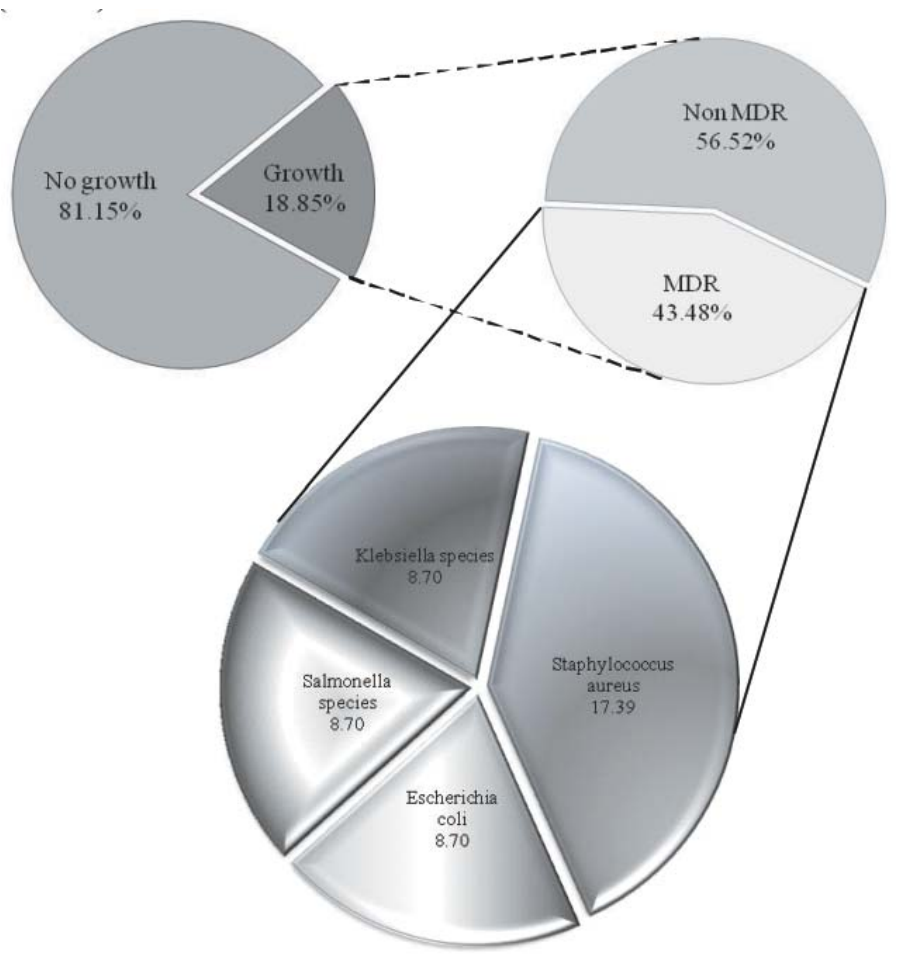

Figure 1: Distribution of organisms in the samples with MDR isolates

Five honey samples were also collected from The Beekeeping Shop, Lalitpur. Four of the samples were from single floral source, which nectar is collected by different colonies of Apis mellifera. One sample (Wild) was from mixed flower source, collected by Apis dorsata.

Table 1: Physical property of honey samples

\begin{tabular}{|c|c|c|c|c|}
\hline Honey type & Floral source & Bee variety & Colour ${ }^{*}$ & $\begin{array}{c}\text { Specific gravity } \\
\text { at } \mathbf{R T}^{\dagger}\end{array}$ \\
\hline Buckwheat & $\begin{array}{c}\text { Fagopyrum esculentum } \\
\text { (Buckwheat) }\end{array}$ & Apis mellifera & $\begin{array}{l}\text { 038R, 018G, 017B Or } \\
\text { Hex\#261211 }\end{array}$ & 1.4 \\
\hline Chiuri & $\begin{array}{c}\text { Diploknema butyracea (Nepali } \\
\text { butter tree) }\end{array}$ & Apis mellifera & $\begin{array}{l}\text { 079R, 071G, 032B Or } \\
\text { Hex\#4F4720 }\end{array}$ & 1.7 \\
\hline Mustard & Brassica campestris (Mustard) & Apis mellifera & $\begin{array}{c}\text { 245R, 235G, 097B Or } \\
\text { Hex\#F5EB61 }\end{array}$ & 1.5 \\
\hline Rudilo & $\begin{array}{l}\text { Pogostemon benghalensis } \\
\text { (Rudilo) }\end{array}$ & Apis mellifera & $\begin{array}{l}\text { 131R, 100G, 036B Or } \\
\text { Hex\#836424 }\end{array}$ & 1.45 \\
\hline Wild & Wild or mixed floral source & Apis dorsata & $\begin{array}{l}\text { 102R, 026G, 000B Or } \\
\text { Hex\#661A00 }\end{array}$ & 1.32 \\
\hline
\end{tabular}

*Red Green Blue format in upper line, and hexadecimal code in lower line, data taken in average tRoom temperature

\section{Antibiotic susceptibility pattern of different isolates}

\section{Staphylococcus aureus}

Oxacillin resistant (MRSA) Staphylococcus aureus were selected for this study. They were also Gentamicin resistant. These organisms showed variable inhibition zone when honey was incorporated with these antibiotics. In average, the susceptibility of the organism was increased by $3 \mathrm{~mm}$ for Chloramphenicol and Cotrimoxazole, $2 \mathrm{~mm}$ for Ciprofloxacin and Gentamicin. The increase by $8 \mathrm{~mm}$ in average was seen when honey sample was added in Oxacillin for the susceptibility test (Table 2). 
Table 2: Zone of inhibition of Antibiotic and Antibiotic incorporated with honey for Staphylococcus aureus

\begin{tabular}{lccccc}
\hline & Mean & S.E.\# & SD & Minimum & Maximum \\
\hline Chloramphenicol & 26.5 & 0.8 & 3.59 & 21 & 30 \\
Chloramphenicol with honey & 29.65 & 1.41 & 6.33 & 17 & 40 \\
Ciprofloxacin & 23.75 & 0.85 & 3.8 & 19 & 29 \\
Ciprofloxacin with honey & 25.9 & 0.95 & 4.27 & 19 & 38 \\
Cotrimoxazole & 21.25 & 0.44 & 1.97 & 18 & 23 \\
Cotrimoxazole with honey & 24.35 & 0.7 & 3.12 & 19 & 30 \\
Gentamicin & 20 & 0.93 & 4.17 & 15 & 26 \\
Gentamicin with honey & 24.15 & 1.21 & 5.43 & 14 & 34 \\
Oxacillin & 12.5 & 0.95 & 4.26 & 7 & 17 \\
Oxacillin with honey & 20.5 & 1.84 & 8.22 & 0 & 38 \\
\hline
\end{tabular}

\# $_{\text {Standard Error of Mean }} \S{ }_{S}$ tandard Deviation

\section{Escherichia coli}

At least one among Amoxycillin-Clavulanic acid, Ceftazidime, Ceftriaxone, Ciprofloxacin, and Cotrimoxazole resistant $E$. coli was taken to detect the synergism. Figure 2 shows that there is slight change in susceptibility pattern when honey was incorporated with the antibiotics. However, there was no statistical difference in T-score (Table 3) except gentamicin $(\mathrm{p}>0.01)$ and the correlation was strongly positive for the same antibiotic $(\mathrm{p}<<0.01)$. Other antibiotics could not show statistical significance in T-score and correlation $(p>0.01)$ (Table 3).

Table 3: T-statistics and correlation of antibiotics with antibiotics and honey for E. coli

\begin{tabular}{lcccc}
\hline \multicolumn{1}{c}{ Variables } & T score & p-value & R (correlation) & p-value \\
\hline amoxyclav and amoxyclav with honey & 1.217 & 0.255 & -0.358 & 0.31 \\
ceftazidime and ceftazidime with honey & 3.337 & 0.009 & 0.25 & 0.486 \\
ceftriaxone and ceftriaxone with honey & 1.637 & 0.136 & 0.448 & 0.194 \\
chloramphenicol and chloramphenicol with honey & -0.238 & 0.817 & 0.560 & 0.092 \\
cotrimoxazole and cotrimoxazole with honey & 2.297 & 0.047 & 0.287 & 0.421 \\
gentamicin and gentamicin with honey & 3.000 & 0.015 & 1.000 & $<0.001$ \\
\hline
\end{tabular}

\section{Klebsiella species}

For the study, Klebsiella species used were resistant to Amoxycillin-Clavulanic acid, Ceftazidime, Ceftriaxone, Ciprofloxacin, Cotrimoxazole and/or Gentamicin, but all were susceptible to Chloramphenicol. On the test, there was sudden increase in susceptibility with the combination of honey and antibiotics (Figure 2). Ceftazidime, ceftriaxone, and chloramphenicol had shown significant synergism $(\mathrm{p}<<0.01)$ and among them, chloramphenicol showed strong positive relation ( $\mathrm{R}=82.7 \%)$ with honey but a slight negative relation $(R=-6 \%)$ between ceftriaxone and honey (Table 4).

Table 4 T-statistics and correlation of antibiotics with antibiotics and honey for Klebsiella species

\begin{tabular}{|c|c|c|c|c|}
\hline Variables & T score & p-value & R (correlation) & p-value \\
\hline amoxyclav and amoxyclav with honey & 2.984 & 0.015 & 0.00 & 1.000 \\
\hline ceftazidime and ceftazidime with honey & 5.155 & 0.001 & 0.342 & 0.333 \\
\hline ceftriaxone and ceftriaxone with honey & 4.287 & 0.002 & -0.06 & 0.869 \\
\hline chloramphenicol and chloramphenicol with honey & 10.301 & $<0.001$ & 0.827 & 0.003 \\
\hline cotrimoxazole and cotrimoxazole with honey & 0.404 & 0.696 & -0.720 & 0.019 \\
\hline
\end{tabular}

\section{Salmonella species}

Ceftazidime, Cotrimoxazole and/or Gentamicin resistant Salmonella species were used for this study. Except Ciprofloxacin $(\mathrm{R}=-89.4 \%, \mathrm{p}<<0.01)$, all other antibiotics showed enhanced inhibition zone when honey was incorporated, but could not show the significant statistical difference $(p>0.01)$ (Table 5). 
Table 5: T-statistics and correlation of antibiotics with antibiotics and honey for Salmonella species

\begin{tabular}{lllll}
\hline Variables & t score & p-value & R (correlation) & p-value \\
\hline amoxyclav and amoxyclav with honey & 3.972 & 0.003 & 0.715 & 0.02 \\
ceftazidime and ceftazidime with honey & 1.374 & 0.203 & -0.186 & 0.606 \\
ceftriaxone and ceftriaxone with honey & 1.134 & 0.286 & 0.502 & 0.139 \\
chloramphenicol and chloramphenicol with honey & 2.160 & 0.059 & -0.492 & 0.148 \\
ciprofloxacin and ciprofloxacin with honey & -0.519 & 0.616 & -0.894 & 0.000 \\
cotrimoxazole and cotrimoxazole with honey & 2.067 & 0.069 & -0.279 & 0.436 \\
gentamicin and gentamicin with honey & 3.000 & 0.015 & 1.000 & $<0.001$ \\
\hline
\end{tabular}

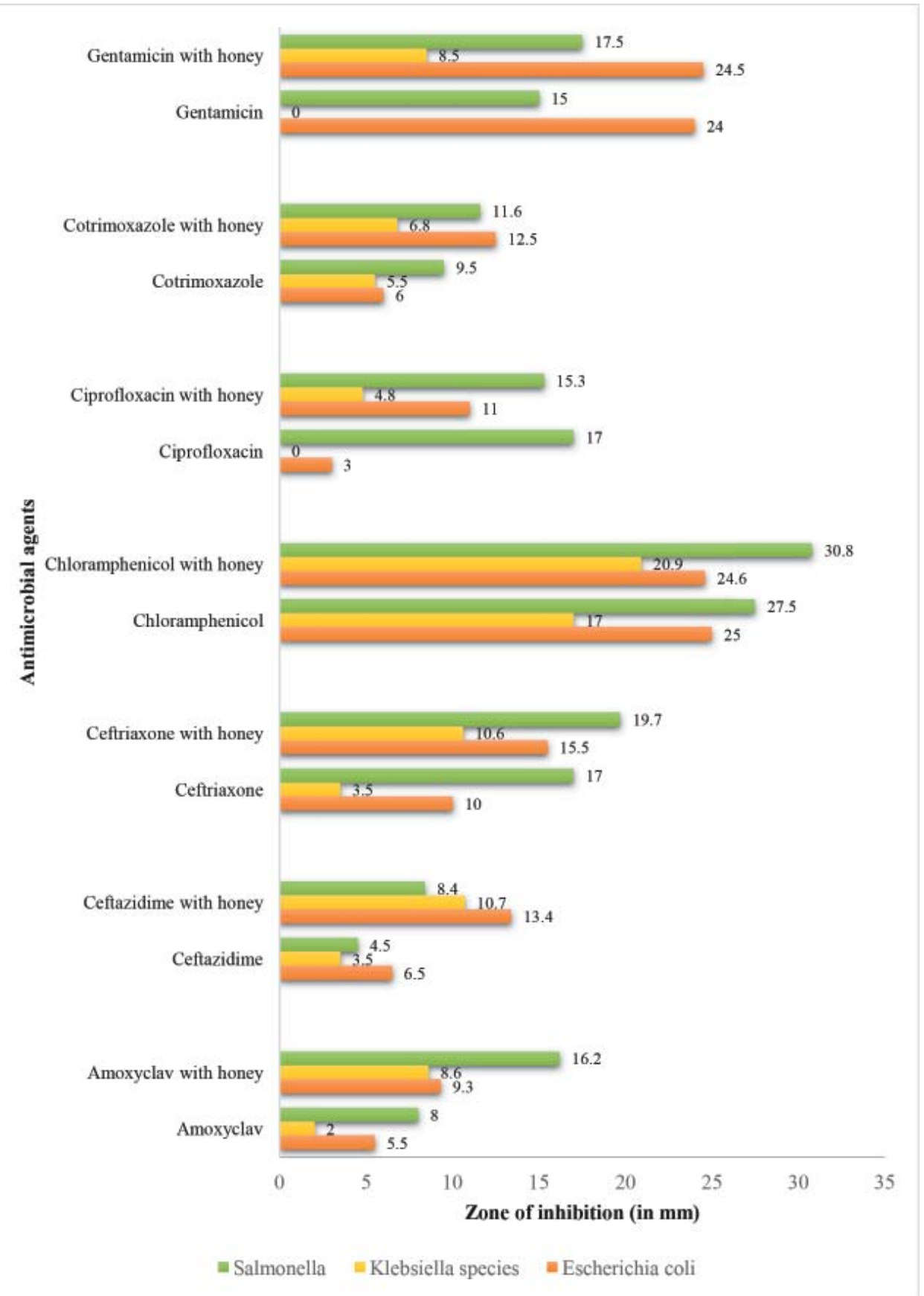

Figure 2: Comparative chart of Zone of inhibition for Enterobacteriaceae between antibiotics and antibiotics with honey 


\section{Pseudomonas aeruginosa}

When metallo $\beta$-lactamase producing (MBL) Ps. aeruginosa were used, there was a drastic and significant increase in zone of inhibition $(\mathrm{p}<<0.01)$ (Figure 3). But the relation was not much stronger and lies between $8 \%$ to $41.9 \%$ (Table 6 ).

Table 6 T-statistics and correlation of antibiotics with antibiotics and honey for Pseudomonas aeruginosa

\begin{tabular}{lcccc}
\hline \multicolumn{1}{c}{ Variables } & t score & p-value & R (correlation) & p-value \\
\hline ciprofloxacin and ciprofloxacin with honey & 8.444 & $<0.001$ & 0.419 & 0.228 \\
gentamicin and gentamicin with honey & 16.058 & $<0.001$ & 0.082 & 0.821 \\
imipenem and imipenem with honey & 8.508 & $<0.001$ & 0.103 & 0.776 \\
\hline
\end{tabular}

\section{Acinetobacter species}

MBL Acinetobacter species showed decreased susceptibility with Ciprofloxacin and Imipenem when honey was added (Figure 3). It was found that there was $28.9 \%$ relation of honey with Ceftazidime and $-4.9 \%$ with Gentamicin (Table 7 ).

Table 7: T-statistics and correlation of antibiotics with antibiotics and honey for Acinetobacter species

\begin{tabular}{|c|c|c|c|c|}
\hline Variables & t score & p-value & $\mathbf{R}$ (correlation) & p-value \\
\hline ceftazidime and ceftazidime with honey & 3.955 & 0.003 & 0.289 & 0.417 \\
\hline ceftriaxone and ceftriaxone with honey & 0.631 & 0.544 & 0.071 & 0.846 \\
\hline ciprofloxacin and ciprofloxacin with honey & -0.303 & 0.768 & 0.296 & 0.406 \\
\hline cotrimoxazole and cotrimoxazole with honey & 2.666 & 0.026 & 0.095 & 0.795 \\
\hline gentamicin and gentamicin with honey & 0.923 & 0.380 & -0.049 & 0.894 \\
\hline imipenem and imipenem with honey & -0.419 & 0.685 & 0.921 & $<0.001$ \\
\hline
\end{tabular}

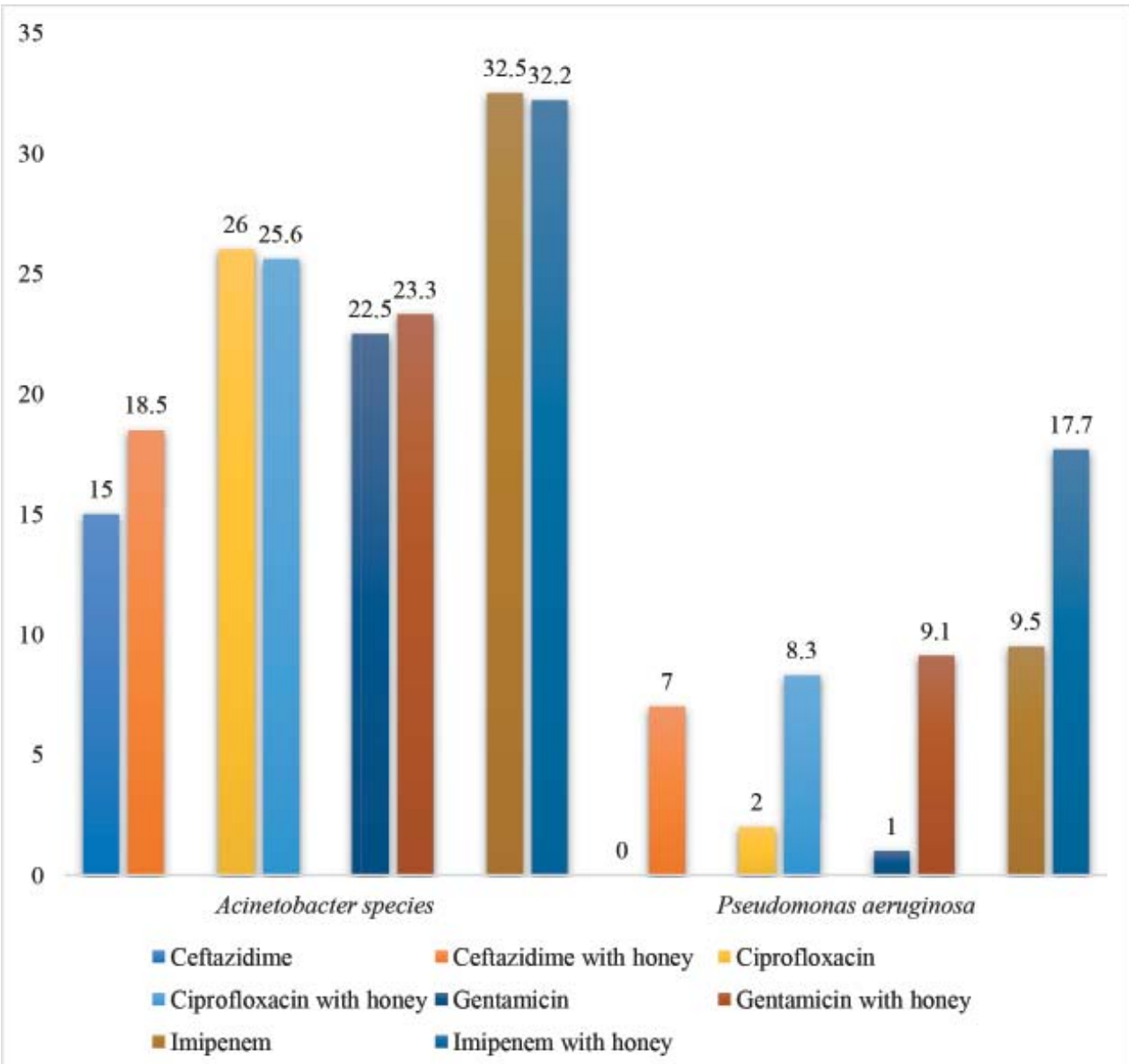

Figure 3: Zone of Inhibition of Antibiotic and Antibiotic incorporated with honey for Acinetobacter species and Pseudomonas aeruginosa 


\section{Susceptibility test to honey compared via ANOVA}

In this study among the 6 bacterial samples used, honey was found to be most effective against $S$. aureus $(\bar{X}=21.2 \pm 4.44 \mathrm{~mm})$ and the effect was decreased gradually to Acinetobacter species $(\bar{X}=18.2 \pm 2.49 \mathrm{~mm})$, Pseudomonas species $(\bar{X}=7.2 \pm 1.10 \mathrm{~mm})$, Klebsiella species $(\bar{X}=6 \pm 2.45 \mathrm{~mm})$, E. coli $(\bar{X}=5.4 \pm 3.58 \mathrm{~mm})$ and Salmonella species showed lowest inhibition zone $(\bar{X}=5.2 \pm 1.30 \mathrm{~mm})$ for the honey.
When the relation between the groups was compared, null hypothesis that average ZOI differences in different groups are equal is rejected. It means the inhibition is variable among the bacteria $(\mathrm{F}=39.17, \mathrm{p}<0.05)$. From means plot, it was found that $S$. aureus and Acinetobacter species were highly susceptible whereas Ps. aeruginosa and organisms of Enterobacteriaceae family are less susceptible to honey (Figure 4).

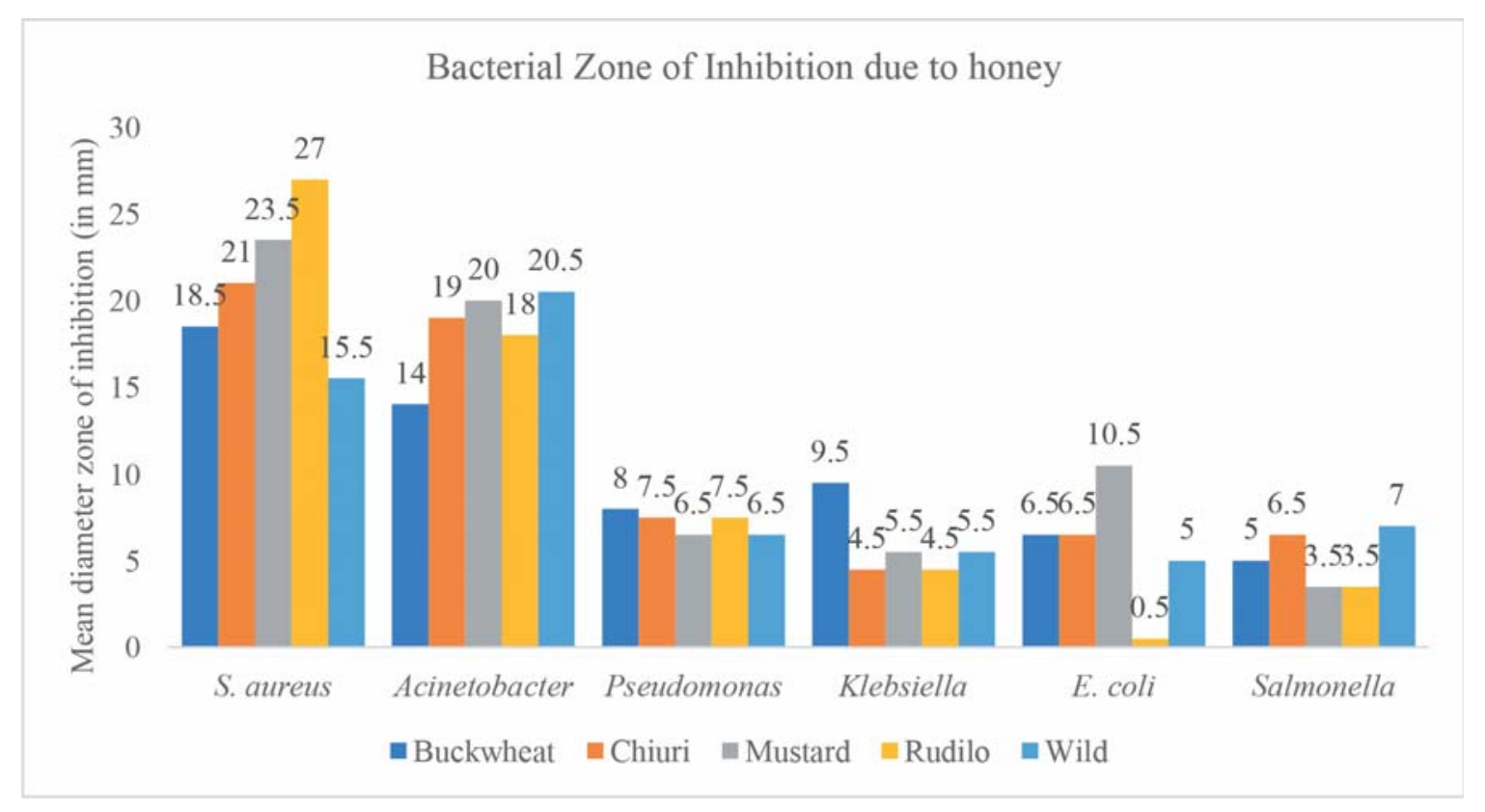

Figure 4: Clustered bar chart of Zone of Inhibition of different bacteria by different honey samples

\section{DISCUSSION}

The antibacterial and antifungal effect of honey has been repeatedly noticed from ancient time. The traditional method of treatment using honey is a remarked gateway for the study of microbiology. The advancement of tools and techniques and modernization of the lifestyle has reduced the use of honey. Antibiotics are now gaining their path as the first selection for the treatment of bacterial infection. This caused uncontrollable increase in drug resistant organisms. Pokhrel (2004) found that $47.57 \%$ pathogens in sputum and $60.40 \%$ pathogens in urine were MDR. Bomjan (2005) found that $60 \%$ urinary and sputum isolates were MDR pathogens. This study shows $43.48 \%$ multi-drug resistant organisms were isolated from various samples. These data show that the distribution of MDR pathogens is different on different geographical areas within Nepal. Indiscriminate \& inadequate use of antibiotics causes losing their potency against various types of organisms
(Bajaj et al. 2018). Due to the different properties of honey, it is used traditionally for treatment of different infections of wound, burns and blood infections (Sharp 2009). Thus the synergism of antibiotics and honey is an interest of study.

In this study, 5 honey types derived from different floral sources were screened for their antibacterial activity. Initial screening with the Kirby Bauer disc diffusion method demonstrated that all tested honey types exhibited more or less susceptibility to all the clinical bacterial isolates used. S. aureus showed greater sensitivity and the members of Enterobacteriaceae were less sensitive to honey. This finding is in accordance with the findings of previous studies (Abd-El et al. 2007, Moussa et al. 2012, Ahmed et al. 2013). These results are very much important for clinical implementation such as wound and burn management (Sufya et al. 2014).

Antibacterial activity of honey can be described due 
to different factors. Due to low water concentration of honey and its hygroscopic nature, its osmophilic activity extracts water from bacteria and makes the organism inactive. The acidic $\mathrm{pH}$ inactivates the organism enzymes for metabolism and thus the organisms are inhibited. In addition, glucose oxidase obtained from bee gut that is regurgitated by bee during honey making process, degrades glucose to produce hydrogen peroxide. The $\mathrm{H}_{2} \mathrm{O}_{2}$ oxidises the organism enzyme and is inactivated and leads to its death. Different phytochemicals like methyl glyoxal and methyl syringate from the floral source is taken by bee during collecting nectar. These metabolites coordinates with the acidic $\mathrm{pH}$ to act for the bacterial inhibition. Recently, other components were also identified in honey that help it as antibacterial effect. Catalase, Maillard reaction products, polyphenols, ascorbic acid, bee defensin-1 protein are some of them (Bizerra et al. 2012).

In different studies, significant synergism was found between honey and antibiotics when tested in vitro. Honcrivine (honey plus acriflavine $0.1 \%$ ) is efficient for debridement of wound without any inflammatory or allergic responses (Efem 2009) which is due to activation of protease due to $\mathrm{H}_{2} \mathrm{O}_{2}$ from honey dressing (Lane et al. 2019). In a study for 16 clinical pathogens including S. aureus, Salmonella species, Streptococcus pyogenes, $B$. cereus and B. subtilis, were up to $60 \%$ more resistant than equal reference strains, and concluded for variability in the antibacterial effect of honey (Voidarou et al. 2011). A research in Pakistan has concluded that methyl glyoxal can be a good inhibitory agent against MDR and non-MDR Salmonella and other Gram-negative organisms (Afzal et al. 2018).

This study found increased zone of inhibition when honey is added to antibiotics. Though the reason behind the synergism is not clear, a study described the synergism of methylglyoxal (found in natural honey) with Piperacillin, a $\beta$-lactam antibiotic. But a study in New Zealand concluded methylglyoxal is not the sole factor for Manuka honey to act synergistically with rifampicin against MRSA (Jenkins and Cooper 2012). From these studies it can be concluded that various factors are responsible for the synergistic or antagonistic action of antibiotics with honey.

In this study, honey showed synergetic effect with Gentamicin against E coli and Salmonella species, with Chloramphenicol against Klebsiella species $(\mathrm{R}=82.7 \%)$ and with Ceftazidime against Acinetobacter species. The results are incompatible with the results of a study performed by Karayil et al. in 1998, where antibiotics Gentamicin, Amikacin and Ceftazidime were synergetic with honey against Pseudomonas species and not with Klebsiella species. This leads to the mystery if the organisms in different geography can lead to different synergism or changing their genetic behaviour with time lapse.

\section{CONCLUSION}

Honey is found to be very effective against Staphylococcus infection whereas it is least effective against $E$. coli. The synergetic effect of honey with different antibiotics are found to be effective against $S$. aureus, Pseudomonas aeruginosa and the members of Enterobacteriaceae family involved in this study but found to be less or no effective against Acinetobacter species.

\section{ACKNOWLEDGEMENTS}

We are most grateful to the Executive Officers of Korea Nepal Friendship Hospital for providing the clinical facilities and support. We are thankful too Mr. Saroj Chandra Lohani for providing the metallo- $\beta$-lactamase producing Pseudomonas aeruginosa and Acinetobacter species for this study. We also express admiration towards the director of the Beekeeping Shop and Research Centre for providing the valuable bee honey samples and the priceless information about them. Our hearty gratitude to the faculties and laboratory staffs of Tri-Chandra Multiple Campus for their support and help to complete this study.

\section{REFERENCES}

Abd-El AAM, El-Hadidy MR, El-Mashad NB and ElSebaie AH (2007) Antimicrobial effect of bee honey in comparison to antibiotics on organisms isolated from infected burns. Ann Burns Fire Disasters 20: 83-88.

Afzal RK, Hannan A, Ahmed SA and Khalid F (2018) Antibacterial activity of methyl glyoxal against multi-drug resistant Salmonella typhi. Pakistan Armed Forces Medical Journal 68: 24-28.

Ahmed M, Djebli N, Aissat S, Khiati B, Meslem A and Bacha SJ (2013) In vitro activity of natural honey alone and in combination with curcuma starch against Rhodotorula mucilaginosa in correlation with bioactive compounds and diastase activity. Asian Pac J Trop Biomed 3: 816-821. 
Bajaj P, Chowdhury SK, Yucha R, Kelly EJ and Xiao GJ (2018) Emerging kidney models to investigate metabolism, transport, and toxicity of drugs and xenobiotics 46: 1692-1702.

Bizerra FC, DaSilva PI and Hayashi MAF (2012) Exploring the antibacterial properties of honey and its potential. Front Microbiol 3: 1-2.

Bomjan R (2005) Prevalence of multidrug resistant strains with reference to Extended-spectrum beta-lactamase producing strains among the bacterial pathogens isolated from different clinical samples at Tribhuvan University Teaching Hospital. M. Sc. Dissertation submitted to the Department of Microbiology, Tribhuvan University, Kathmandu, Nepal.

Boukraâ L and Sulaiman SA (2009) Rediscovering the antibiotics of the hive. Recent patents on antiinfective drug discovery 4: 206-213.

CLSI (2011) Performance Standards for Antimicrobial Susceptibility Testing; Twenty-First Informational Supplement. CLSI document M100-S21. Wayne, PA, Clinical and Laboratory Standards Institute.

Efem SE (2009) Clinical observations on the use of honcrivine in the chemical debridement of wounds Niger J Clin Pract 12: 412-415.

Irish J, Blair S and Carter DA (2011) The Antibacterial Activity of Honey Derived from Australian Flora. PLOS ONE 6: e18229

Jawad MAH. (2011) Antimicrobial effect of bee honey on some pathogenic bacteria isolated from infected wounds in comparison to commonly used antibiotics. J Basrah res 37: 78-83.

Jenkins R and Cooper R (2012) Improving antibiotic activity against wound pathogens with manuka honey in vitro. PLoS One 7: e45600.

Jenkins R, Burton N and Cooper R (2011) Effect of manuka honey on the expression of universal stress protein A in meticillin-resistant Staphylococcus aureus. Int J Antimicrob Agents 37: 373-376.

Karayil S, Deshpande SD and Koppikar GV (1998) Effect of honey on multidrug resistant organisms and its synergistic action with three common antibiotics J Postgrad Med 44: 93-96.
Lane JA, Calonne J, Slattery H and Hickey RM (2019) Oligosaccharides Isolated from MGO Manuka Honey Inhibit the Adhesion of Pseudomonas aeruginosa, Escherichia coli O157:H7 and Staphylococcus aureus to Human HT-29 cells. Foods 8.

Lu J, Carter DA, Turnbull L, Rosendale D, Hedderley D, Stephens J, Gannabathula S, Steinhorn G, Schlothauer RC, Whitchurch CB and Harry EJ (2013). The effect of New Zealand kanuka, manuka and clover honeys on bacterial growth dynamics and cellular morphology varies according to the species. PLoS One 8: e55898.

Molan PC (1992) The antibacterial activity of honey. 2. Variation in the potency of the antibacterial activity. Bee World 73: 59-76.

Molan PC and Rhodes T (2015) Honey: a biologic wound dressing.

Müller P, Alber DG, Turnbull L, Schlothauer RC, Carter DA, Whitchurch CB and Harry EJP (2013) Synergism between Medihoney and rifampicin against methicillin-resistant Staphylococcus aureus (MRSA) 8: e57679.

Nassar HM, Li M and Gregory RL (2012) Effect of Honey on Streptococcus mutans Growth and Biofilms Formation. App Env Microbiol 78: 536540.

Pimentel RB, da Costa CA, Albuquerque PM and Junior SD (2013) Antimicrobial activity and rutin identification of honey produced by the stingless bee Melipona compressipes manaosensis and commercial honey BMC Complement Altern Med 13: 151.

Pokhrel BM (2004) A handbook of Clinical Microbiology. Gorakhnath Desktop and Printing Supports, Kathmandu, Nepal.

Sahm DF, Thornsberry C, Mayfield DC, Jones ME, Karlowsky JA (2001) Multidrug-resistant urinary tract isolates of Escherichia coli: prevalence and patient demographics in the United States in 2000. Antimicrob Agents Chemother 45:1402-1406

Shang K, Wei B, Jang HK, and Kang M (2019) Phenotypic characteristics and genotypic correlation of antimicrobial resistant (AMR) Salmonella isolates from a poultry slaughterhouse and its 
downstream retail markets. Food Control 100: 3545.

Sharp A (2009) Beneficial effects of honey dressings in wound management. Nurs Stand 24: 66-72.

Stagos D, Soulitsiotis N, Tsadila C, Papaeconomou S, Arvanitis C, Ntontos A, Karkanta F, AdamouAndroulaki S, Petrotos K, Spandidos DA, Kouretas D and Mossialos D (2018) Antibacterial and antioxidant activity of different types of honey derived from Mount Olympus in Greece. Int J Mol Med 42: 726-734.

Sufya N, Matar N, Kaddura R and Zorgani A (2014) Evaluation of bactericidal activity of Hannon honey on slowly growing bacteria in the chemostat. Drug Health Patient Saf 6: 139-144.
Tramuta C, Nebbia P, Robino P, Giusto G, Gandini M, Chiado-Cutin S and Grego E (2017) Antibacterial activities of Manuka and Honeydew honey-based membranes against bacteria that cause wound infections in animals. Schweiz Arch Tierheilkd 159: 117-121.

Voidarou C, Alexopoulos A, Plessas S, Karapanou A, Mantzourani I, Stavropoulou E, Fotou K, Tzora A, Skoufos I and Bezirtzoglou EJA (2011) Antibacterial activity of different honeys against pathogenic bacteria. 17: 375-379.

Wijesinghe M, Weatherall M, Perrin K and Beasley R (2009) Honey in the treatment of burns: a systematic review and meta-analysis of its efficacy. N Z Med J 122: 47-60. 